\title{
One-pot synthesis of Polyoxometalate
}

\section{decorated polyindole for the high energy}

\section{storage supercapacitors}

Anjana Anandan Vannathan, ${ }^{[a]}$ Tatinaidu Kella, ${ }^{[b]}$ Debaprasad Shee, ${ }^{[b]}$ and Sib Sankar $M a l^{*[a]}$

[a] Materials and Catalysis Laboratory, Department of Chemistry, National Institute of Technology Karnataka, Surathkal 575025, India

[b] Department of Chemical Engineering, Indian Institute of Technology Hyderabad, Kandi, Sangareddy 502285, Telangana, India

*Correspondences should be addressed: malss@nitk.edu.in 

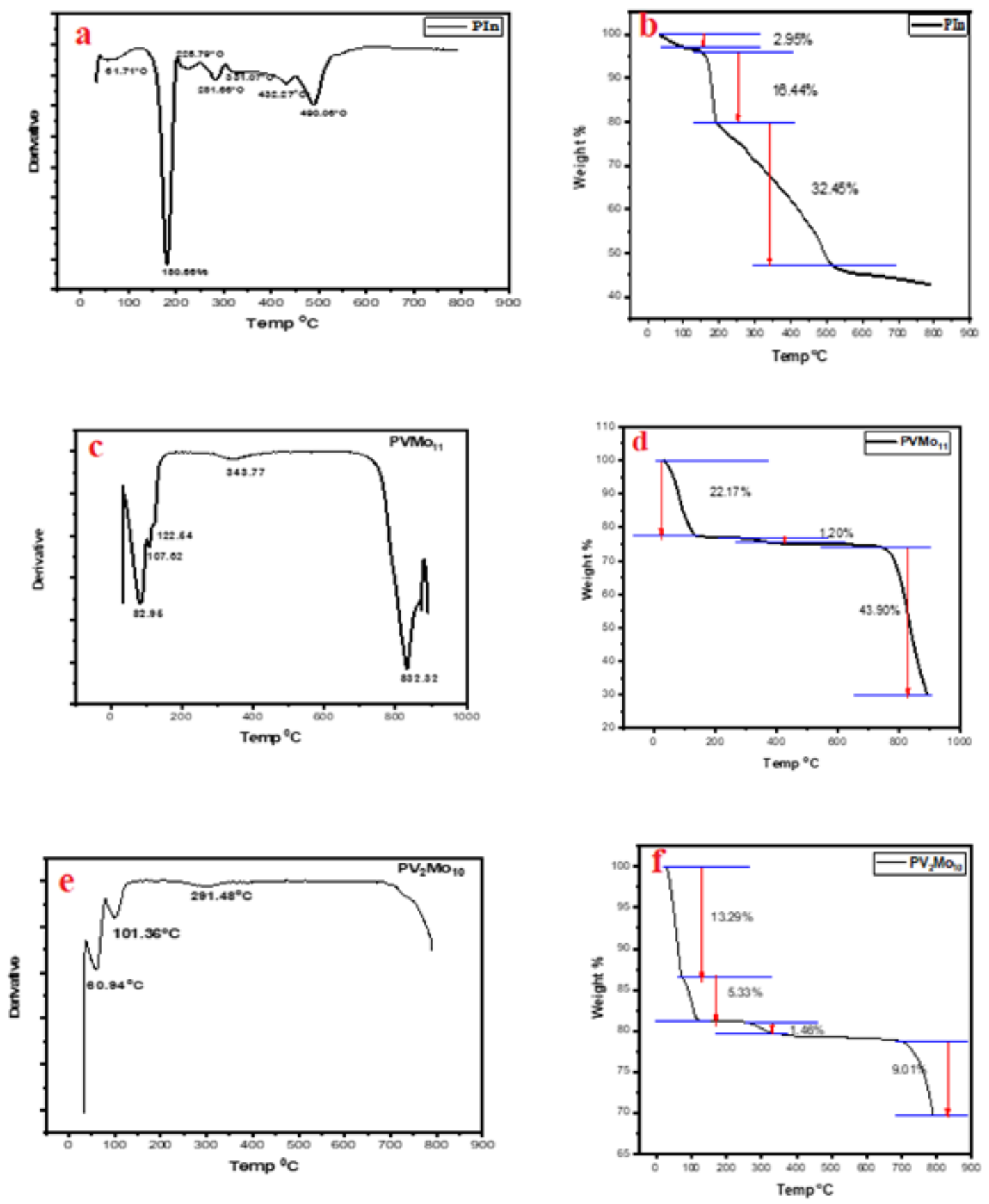

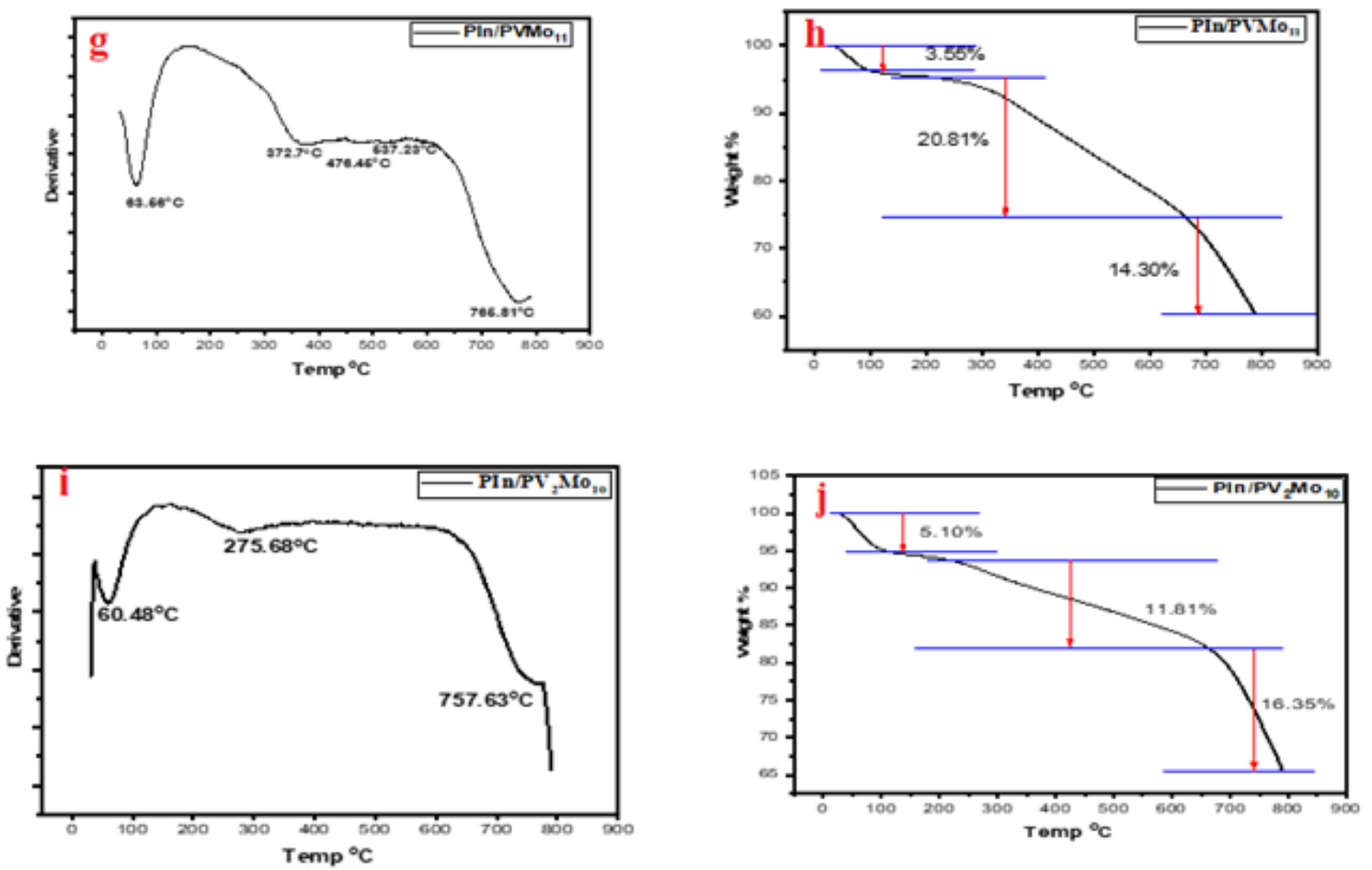

Figure S1: TGA curves of temperature vs weight loss of a, c, e, g, and i correspond to PIn, $\mathrm{H}_{4}\left[\mathrm{PVMo}_{11} \mathrm{O}_{40}\right], \mathrm{H}_{5}\left[\mathrm{PV}_{2} \mathrm{Mo}_{10} \mathrm{O}_{40}\right]$, $\mathrm{PIn} / \mathrm{PVMo}_{11}$, and $\mathrm{PIn} / \mathrm{PV}_{2} \mathrm{Mo}_{10}$, respectively. The first derivative of TGA curves of $\mathrm{PIn}, \mathrm{H}_{4}\left[\mathrm{PVMo}_{11} \mathrm{O}_{40}\right], \mathrm{H}_{5}\left[\mathrm{PV}_{2} \mathrm{Mo}_{10} \mathrm{O}_{40}\right]$, $\mathrm{PIn} / \mathrm{PVMo}_{11}$, and PIn/PV $\mathrm{Mo}_{10}$ and shown in b, d, f, h, and $\mathrm{j}$. 

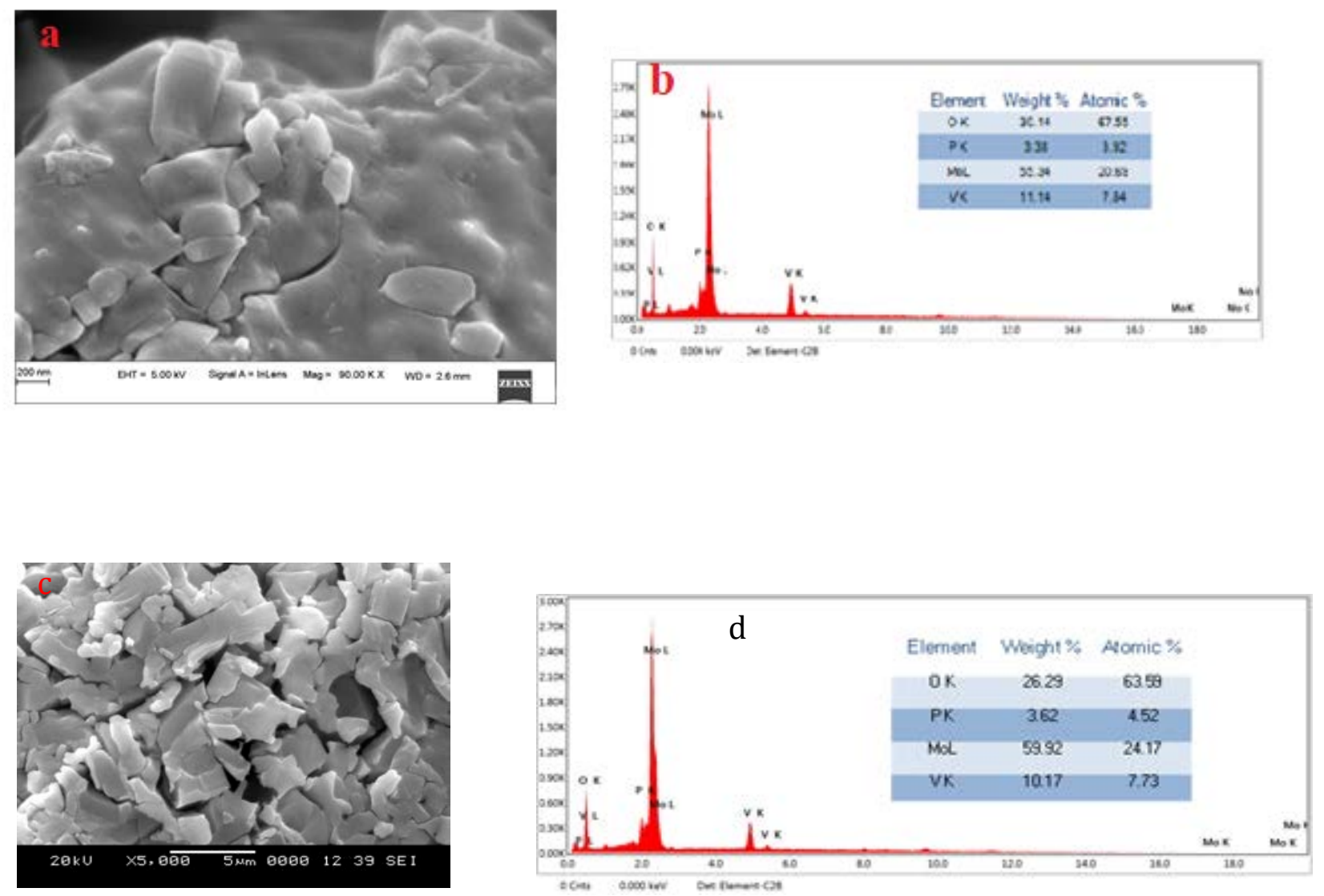

Figure S2: FESEM and EDX of a) and b) Pure $\mathrm{H}_{4}\left[\mathrm{PVMo}_{11} \mathrm{O}_{40}\right]$, and c) and d) Pure $\mathrm{H}_{5}\left[\mathrm{PV}_{2} \mathrm{Mo}_{10} \mathrm{O}_{40}\right]$ 


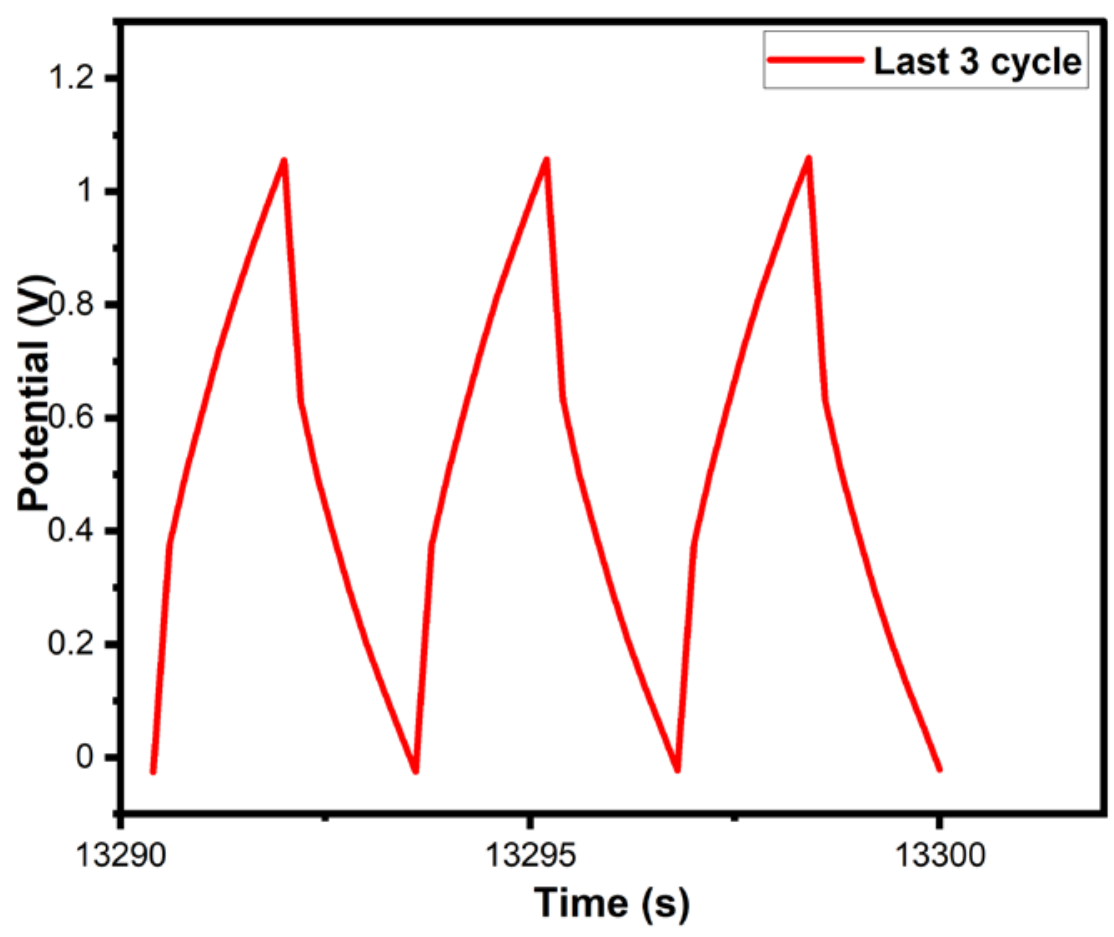

Figure S3: Last three cycles of $\mathrm{PIn} / \mathrm{PV}_{2} \mathrm{Mo}_{10}$ based on GCD.
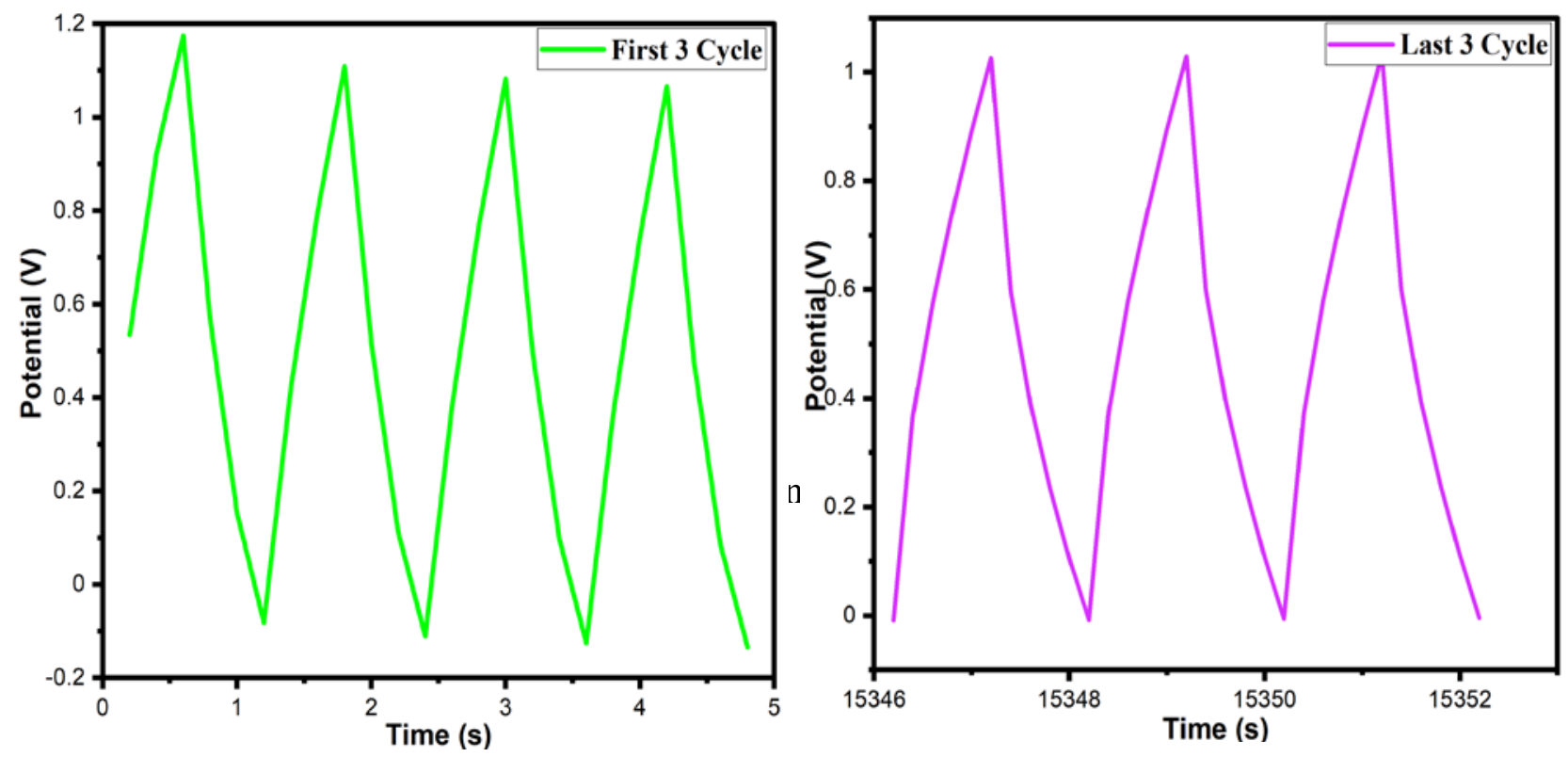

Figure S4: $1^{\text {st }}$ and Last three cycles of PIn/PVMo 11 based on GCD. 

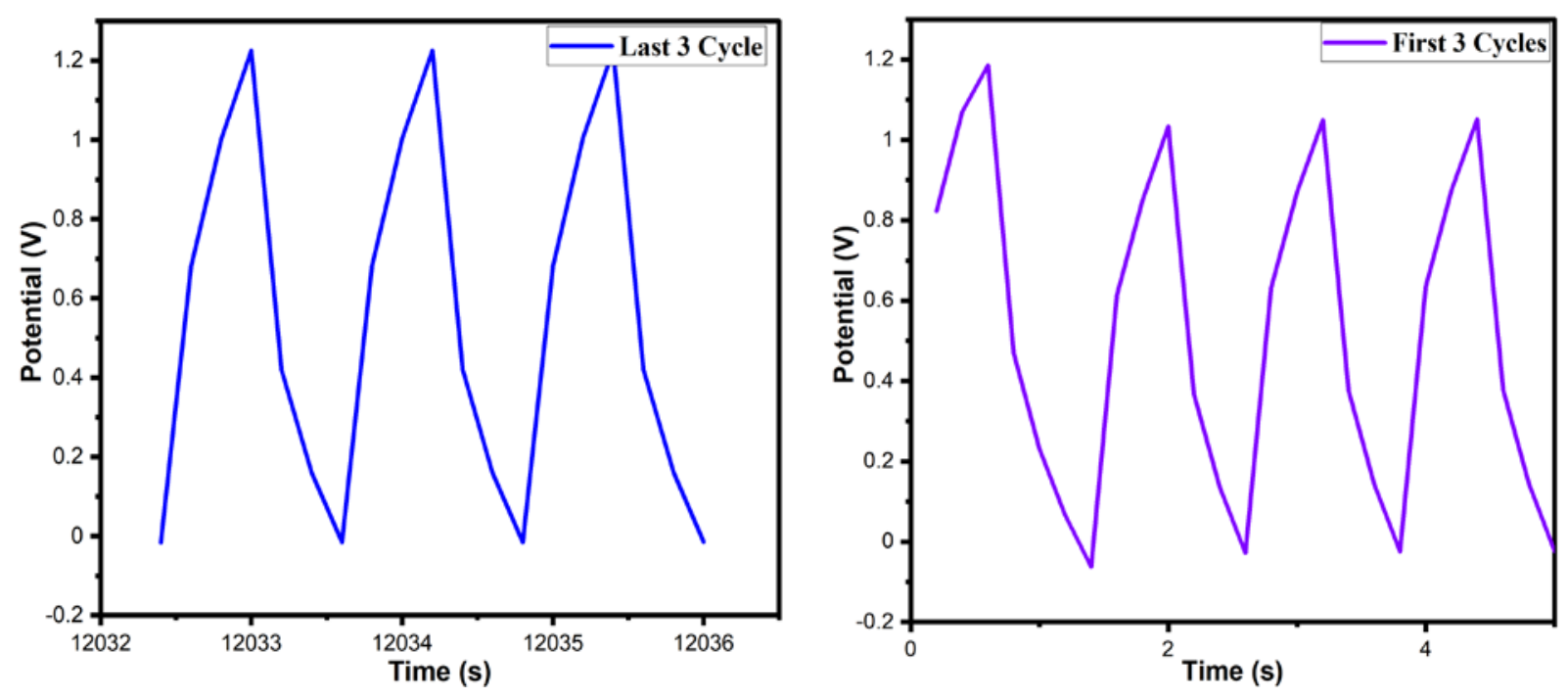

Figure S5: $1^{\text {st }}$ and Last three cycles of PIn based on GCD.

Table S1: Specific capacitance of PIn, PIn/PVMo11, and PIn/PV ${ }_{2} \mathrm{Mo}_{10}$ composites without IR drops at different current densities.

\begin{tabular}{|c|c|c|c|c|}
\hline Materials & $\begin{array}{c}\text { Current } \\
\text { Density (A/g) }\end{array}$ & $\begin{array}{c}\text { Specific } \\
\text { Capacitance } \\
(\mathrm{F} / \mathrm{g})\end{array}$ & $\begin{array}{c}\text { Energy } \\
\text { Density } \\
(\mathrm{Wh} / \mathrm{kg})\end{array}$ & $\begin{array}{c}\text { Power Density } \\
\text { (W/kg) }\end{array}$ \\
\hline \multirow{3}{*}{ PIn } & 0.2 & 33.50 & 4.65 & 279.00 \\
\cline { 2 - 5 } & 0.4 & 13.12 & 1.82 & 368.66 \\
\cline { 2 - 5 } & 0.6 & 11.03 & 1.53 & 489.53 \\
\cline { 2 - 5 } & 0.8 & 7.55 & 1.049 & 755.78 \\
\hline PIn/PVMo11 & 0.2 & 177.35 & 9.7726 & 178.50 \\
\cline { 2 - 5 } & 0.4 & 126 & 5.89 & 349.97 \\
\cline { 2 - 5 } & 0.6 & 68 & 3.2232 & 473.68 \\
\cline { 2 - 5 } & 0.8 & 50.11 & 2.5321 & 606.38 \\
\cline { 2 - 5 } & 1 & 26 & 1.4824 & 670.23 \\
\hline PIn/PV Mo10 & 2 & 21 & 0.272 & 1192.24 \\
\cline { 2 - 5 } & 0.2 & 198.08 & 10.19 & 198.54 \\
\cline { 2 - 5 } & 0.4 & 154 & 9.10 & 370.94 \\
\cline { 2 - 5 } & 0.6 & 74.8 & 5.23 & 475.56 \\
\cline { 2 - 5 } & 0.8 & 63.15 & 3.50 & 615.94 \\
\cline { 2 - 5 } & 1 & 40.87 & 2.13 & 721.17 \\
\cline { 2 - 5 } & 2 & 27.01 & 1.499 & 1225.21 \\
\hline
\end{tabular}




\section{S1 Calculation:}

The gravimetric specific capacitance and energy density of electrodes were calculated (CV graphs) from the following equations:

Specific capacitance $\left(C_{s}\right): \quad C s=\frac{1}{m \times v \times \Delta V} \int I(V) d V$

where $m, v$, and $\Delta V$ is the mass of active material, scan rate, and potential window, respectively.

$\mathrm{C}=\frac{\int i V d t}{\int_{V_{i}}^{V_{f}} V d V}=\frac{2 i_{m} \int V d t}{V^{2}\left\{\begin{array}{l}V_{f} \\ V_{i}\end{array}\right.}=\frac{i(\Delta t * \Delta V)}{m(\Delta V)^{2}} \mathrm{~F} / \mathrm{g}$

Where I, $\Delta \mathrm{t}$, and $\Delta \mathrm{V}$ represent the current density $(\mathrm{A} / \mathrm{g})$, discharge time $(\mathrm{Sec})$, and operating cell potential (V). The power density (P) and energy density (E) were assessed from the GCD profile using the equations (4) and (5), respectively:

$\mathrm{P}=\frac{E}{\Delta t(s)} \times 3600 \mathrm{~W} / \mathrm{kg}$

$\mathrm{E}=i \int V d t W h / k g$

Where $\mathrm{E}$ is the energy density, $\Delta \mathrm{t}$ is the discharge time in seconds, $\mathrm{C}$ is the capacitance, and $\Delta \mathrm{V}$ is the potential window.

The cell capacitance and impedance were estimated using the EIS data for the device (laboratory scale) applications are applying equations 6, 7, and 8.

$\operatorname{Re}(\mathrm{C})=-\operatorname{Im}(\mathrm{Z}) / \omega \mathrm{IZI}^{2}$.

$\operatorname{Im}(\mathrm{C})=\operatorname{Re}(\mathrm{Z}) / \omega \mathrm{IZI}^{2}$

$\mathrm{C}=\operatorname{Re}(\mathrm{C})+j \operatorname{Im}(\mathrm{C})$

$\mathrm{Z}=\mathrm{SQRT}\left[\operatorname{Re}^{2}(\mathrm{Z})+\operatorname{Im}^{2}(\mathrm{Z})\right]$ 7 
$\operatorname{Re}(\mathrm{C})$ is the real part, and $\operatorname{Im}(\mathrm{C})$ is the intricate part of the capacitance. These two values are determined using the real and imaginary parts of the impedance $(\mathrm{Z})$ values. $\omega$ denotes the angular frequency, where $f_{0}$ is the cut-off frequency or the minimum frequency applied [1].

\section{References}

(1) Taberna, P. L. ; Simon, P. ; Fauvarque, J. F. Electrochemical Characteristics and Impedance Spectroscopy Studies of Carbon-Carbon Supercapacitors. J. Electrochem. Soc. 2003, 150, A292-A300. 